\title{
Women's Narratives on their Interactions with the First Response Police Officer Following an Incidence of Domestic Violence in the UK
}

\author{
Keeling $\mathbf{J}^{*}$, van Wormer, $\mathbf{K}$ and Taylor $\mathbf{P}$
}

University of Chester Merseyside, Merseyside, UK

\begin{abstract}
Background: Historically police responses towards the treatment of domestic disturbances regard them as a noncriminal problem. Recent changes to societal and Criminal Justice System attitudes to domestic violence now places an emphasis on first response officers to effectively deal with offenders, manage victim safety and gather evidence.

Methods: This study explored fifteen women's interactions with the attending first response police officer following an episode of domestic violence within the home. A qualitative approach using unstructured narrative interviews was chosen to ensure that each woman remained in control of the research interview.

Results: Thematic analysis revealed three main themes concerning power relations and officer attitudes, suggesting that personal and cultural factors may negatively impact on officers 'handling of complaints of partner assault, offsetting policy initiatives that guide officers in engaging with victims of domestic violence. The order of the themes reflects the sequential nature of the women's dialogue. The first theme explores the initial police response, followed by the women's narratives around feelings of personal disregard for their experiences and evidential considerations. The final theme explores the police response to retraction of statements.

Conclusions: Women's interactions with first response officers following domestic violence illuminates societal issues previously unmentioned. Making women's' stories visible provides an important insight, contribution and opportunity to examine first response officer's responses to domestic violence. Integrating the voices of the women (service Abstract users) themselves, is arguably an advantageous consideration towards continuing Professional development training for all first response police officers. The attendance of the police at an incident of domestic violence provides unique opportunity to gather evidence for the purposes of prosecution.
\end{abstract}

Negative police responses to women experiencing domestic violence may serve to undermine a woman's autonomy and may also be interpreted as condoning the behavior of the abusive partner.

Keywords: Police officer; Domestic; Awareness; Violence

\section{Introduction}

Historically the police response towards the treatment of domestic disturbances has been to regard them as a noncriminal problem, a private issue to be resolved within the family [1]. However, these societal and Criminal Justice System (CJS) attitudes to domestic violence have been challenged and there has been a deliberate attempt by agencies such as the police to review practices that will both address the pressing need for adequate responses, but at the same time influence the prism by which domestic disturbances, abuse and violence is publically viewed. An awareness of the seriousness of incidents and longer term individual and societal harms has resulted in measures to improve police and other statutory agency responses [2]. Positive responses by agencies involved in detection, arrests, investigation and charging are crucial in conveying that domestic violence is an important area of work [3]. As a result the UK has witnessed the enactment of legislation which has a central objective of bringing the perpetrator to justice. Contemporary policing is not simply understood as solely the activity of the police themselves; rather policing can be contextualised as "the output of a variety of agencies with multiple objectives and lines of accountability" [4]. Policing domestic violence is one such area which necessitates collaborative working with partners from all statutory agencies, including the CPS and courts, responsible for prosecuting and convicting perpetrators as well as voluntary agency personnel who primarily manage victim safety. Despite the myriad of agencies involved in the criminal justice process in cases of domestic violence, the immediate interface between victim and agency is likely to be that of a responding police officer, especially in cases where injuries have been sustained and/or where there is the potential for harm or risk. Given this contact, the character and nature, and the victim's perspective of it, are crucial to understanding police responses to domestic violence. Indeed, the individual behaviours of police officers in this context is an important avenue to investigate, not least as the police are symbolically powerful in terms of intervention [3], but also as a gateway to other criminal justice agencies and come to represent the opening to the beginning of criminal justice as a algorithmic process. Research has highlighted many of the possible barriers and areas of practice that potentially lead to negative experiences and less than desirable

*Corresponding author: June Keeling, Department of Health and Social Care University of Chester. Cheshire, Tel: +441925534065; E-mail: j.keeling@chester.ac.uk

Received April 23, 2015; Accepted May 14, 2015; Published May 21, 2015

Citation: Keeling J, van Wormer, K, Taylor P (2015) Women's Narratives on their Interactions with the First Response Police Officer Following an Incidence of Domestic Violence in the UK. Social Crimonol 3: 122. doi:10.4172/23754435.1000122

Copyright: ( $) 2015$ Keeling J, et al. This is an open-access article distributed under the terms of the Creative Commons Attribution License, which permits unrestricted use, distribution, and reproduction in any medium, provided the original author and source are credited. 
outcomes [5-7]. Legal constraints, officer training and the cultural context in which policing takes place have all undergone significant appraisal. What or who is responsible for poor performance and victim satisfaction in cases of domestic violence remains a contemporary area of research and analysis, with the floating signifier moving across discursive, legislative, policy and cultural boundaries.

\section{Background and Context}

\section{Legal considerations}

An inhibiting factor in making an immediate arrest of the perpetrator is the fact that the rights and vulnerabilities of the accused and the rights and vulnerabilities of the perceived victims must be carefully weighed. The police officer may experience a contradiction between a "perceived lack of powers of arrest" [4], and Article 2 (the right to life) of the Human Rights Act [8], which places an obligation on public authorities to take positive action when there are reasonable preventative operational measures to avoid an immediate risk [9]. Arresting alleged perpetrators for this and other reasons accordingly is a rare occurrence. Without an arrest, the end result is that many victims are disqualified from receiving protection immediately after a domestic violence incident. This is the case despite Section 110 of the Serious Organised Crime and Police Act [10], clearly outlining that powers of arrest have been significantly extended and simplified. Hesitation or a noncommittal to actions or arrest has received some recognition in the domestic violence scholarship. The quality of police action and intervention has been critically reviewed in the Canadian policing context. In Canada, police contacts in situations of family violence have been viewed as frequently unhelpful or ineffective. In a bid to ascertain the extent of police action (or the absence of action), and to explore women's experiences of calls for help in situations of family violence. In an analysis of government interview data on almost 400 women who had contacted the police as a result of the violence, only around half of the women received even a visit from the police; others complained that the perpetrator was not removed from the home when a police visit was made [11]. Similarly, in England and Wales, studies have sought to analyse and interpret the perspectives of domestic violence victims $[12,13]$. Whilst the official and political oratory confirmed the voice of the victim being centralised in the criminal justice process [14] the 'rhetoric-reality' disjuncture in the example of domestic violence remained. Previous studies in the UK, which examined domestic violence pilot programmes in Croydon and Caerphilly, domestic violence victims reported poor satisfaction with some police interventions, in particular the quality of evidence sought by the police [15]. More recently, some victims' loss of trust and confidence in responding police officers [16]. Time delays in attendance and a lack of background knowledge of the circumstances of the incident by attending officers is seen as potentially worsening the experience for the victim. The recognition of familial and domestic disputes by statutory agencies has long been a topic of policy review. The re-occurring motifs of the home as a hidden site of violence, and the apparent delay in, and apathetical approach to, police intervention of the 1980s prompted Home Office responses in the form of a commitment to improvement [17]. Neglect of attention would have represented a portent of doom, and therefore the proposals, which were generative of best practice, were further strengthened through the passing of the Domestic Violence, Crime and Victims Act in 2004. This Act gave the police increased autonomy to effectively deal with offenders whilst crucially managing victim safety. Common assault is an arrest able offence under this Act and, since 2009, under Sections 12 and 13; courts can impose restraining orders protecting victims from harassment even if the perpetrator has been acquitted at trial [18]. Additionally, breaching a civil order becomes a matter for the criminal courts under this Act. Current legislative changes are in part underpinned by recognition of the statistically high prevalence of repeat victimisation. Repeat victimisation compounds suffering on many levels, not least in terms of health, housing and education but crucially, the loss of freedom and autonomy, particularly when episodes of violence are likely to increase in frequency and severity [19].

\section{First response police officer}

Guidelines for investigating domestic violence in the UK emphasise the importance in identifying the primary aggressor, exercising patience and sensitivity when dealing with the victim whilst adhering to the minimum standards of the 'No Witness, No Justice' requirements [20] and a duty of positive action. Operational guidelines recommend interviewing the victim independently and in a secure space where confidentiality is maintained. The officer is presented with a unique opportunity for exercising a needs and risk assessment, gaining consent for access to support services prior to a statement being taken, and, crucially, gathering evidence. Subsequently "unless the officer gets the initial reaction and provision right from the outset, a huge range of other Criminal Justice Service processes can fall down" [21]. However curiously, in relation to domestic violence, officers currently employed within the force do not receive compulsory training in regards to domestic violence [4], thus many are ill equipped to assist in facilitating both safety strategies and successful prosecutions. As the decision to charge rests firmly with the CPS based on the twofold threshold test, it is vital that minimum evidential requirements are met to support a realistic prospect of conviction [22]. The role of the first responding officer in gathering evidence is crucial for effective collaborative working with their CPS partners and prosecution as well. We know from the criminal justice literature, however, that statement retraction by victims is a common occurrence, in spite of, or perhaps because of, the likelihood that the accused will be found guilty at trial. Typically, and so much research would suggest, attrition of criminal cases comes to represent the decision making of a victim in the context of the relationship with the aggressor [23,24]. However, this myopic view may come to resemble a silencing of other potential triggers for the withdrawal of statements from victims, in particular where victims may have little faith in the police's ability to secure prosecution [25]. Given the potential for a multiplicity of reasons for statement withdrawal, and to protect the victim, the process for retracting a statement involves police consultation to ensure there has been no intimidation, followed by a decision made by the CPS as to whether to compel the witness to court. Current legislation makes provision for prosecutions in the absence of the witness albeit this is a highly unusual occurrence. Policy initiatives have been integral in enhancing the support offered to women disclosing domestic violence, to augment the number of women deciding to support the prosecution effort instead of retracting their statements [26]. CPS data illustrates that $31 \%$ of prosecutions resulted in unsuccessful outcomes during 2007/8 [27], and $28.1 \%$ during 2008/9 [28], although it is unclear how many are attributable to victim retraction. Explanations for unsuccessful outcomes offered by the CPS include conflicts in evidence and essential legal elements missing from the prosecution case. Crucially, there is also an acknowledgement that prosecution outcomes are influenced by unreliable witnesses, many of whom are in poor health mentally or physically [22-27]. Police culture and domestic violence the barriers to efficient, sensitive and effective responses to domestic violence cases are not clearly visible. Indeed, as the previous sections have shown, problems have, and potentially continue to exist in this challenging 
area of policing. The procedural obstacles, gradual recognition of domestic violence in official vocabulary, and its partial positioning in the lexicon of crime control and presence of ambiguity have hindered operationalizing effective techniques of crime control and improving satisfaction among victims. Whilst these discursive, rhetorical and administrative hurdles are primary avenues of analysis and past/ proposed reform, the cultural context of policing - and its effects on policing domestic violence - have reinvigorated the contemporary critiques of police practice as Robinson [29]. Eloquently postulates, "Police culture has long been struggling with if and how domestic violence fits into their perspective of what constitutes 'real' police work". The key architects of police culture research such as Jerome Skolnick as well as contemporary analyses performed by writers such as Nigel Fielding and Simon Hold away point to the way in which police culture forms as a critical facet in the conceptualisation of police behaviours and the delivery of this particular public service. Indeed, policing is a manifold image, with a variety of constituent parts feeding into what policing is and how it is undertaken. The informal norms of policing are an important aspect of this, not least at the point where formal rules and informal norms collide. Values, beliefs and issues of informally defined role objectives have received the greatest level of scrutiny from the academic community. Put simply, considering how police officers understand their role, their position within an organisation and how they conceive of their role 'in action' are fundamental in sculpting a discussion of police behaviours and cognitive propensities. Police work, like other areas of the criminal justice process are riven with tensions between aims and practice. Seminal authors [30] have provided useful analytical tools to interrogate value systems that underlie particular approaches to criminal justice work. A marked distinction is evident between a 'due process' model and a 'crime control model'; the former's ideology being constructed on principles of administering justice in accordance with rules that are publicly known, fair and just, and the latter based on the premise that the "repression of criminal conduct is by far the most important function to be performed by the criminal process" [30]. The "crime control' model is illustrative of a series of approaches and behaviours within a system where the demand for finality is high [30]. On the other hand, the 'due process' model aims to eliminate mistakes as far as practicable with a demand for finality of an offence being low. In the area of criminal justice, these models offer a framework for examining the tensions of different value systems which have different priorities [31]. Such understanding that scratch the surface of the public image of criminal justice, and activities such as police work serve a practical usefulness in the area of policing domestic violence. The significance of culture, and its customary values, are important given the necessary changes in the recognition of domestic violence as a police matter. Occupational (sub) cultures are powerful in moulding attitudes towards certain crime types, certain perpetrators and certain victims [29], within a context of contemporaneous bureaucratic and organisational upheaval of public agency work. The links between domestic violence and policing have also taken a dramatic turn in establishing relationships between police officers and domestic violence perpetrators. A review of literature from the United States [32,33] reveals disproportionately high rates of family violence perpetrated by male police officers. The resultant consequence is that one group of women who are reluctant to call the police are the wives of police officers who suffer assault. Domestic violence among police officers, in fact, has gained only relatively recent recognition as a potential problem [34]. Although the research is limited, self-report surveys indicate that the domestic assault rate of male police officers is around two to three times more than that of men in the general population. The picture of the extent of such crimes is further problematized by the fact that most police perpetrators do not have arrest records for this crime as they tend to plead guilty to a lesser charge. Because of the difficulty of sanctioning such officers, the International Association of Chiefs of Police, headed by Nancy Turner, introduced new guidelines to address potentially problematic behaviour. Only a small percentage of departments are following these guidelines [34]. A more recent investigation entitled Fox in the Henhouse, similarly discusses the bias that police officers who themselves have been arrested for domestic violence would have when called to intervene in such cases [32].

\section{Research Design}

\section{Aims and objectives}

There is acknowledgement that prosecution outcomes are affected by both victim issues and the inefficiency of CJS partners during the investigative and prosecution process. However, for many victims the overriding concern may be managing their safety. Accordingly, a desire for recourse through the Criminal Justice System may be a secondary issue. Given that many victims of violence seek immediate help from the police following an incident, further investigation is required to explore why many are unwilling to support the prosecution effort that even in the event of an acquittal at trial would help in securing their immediate safety. The aims of the research were twofold: To advance understandings of victim/survivor experience following their initial interaction with a first responding police officer. To explore the character and nature of the personal interaction between victim/ survivor and police officer in the context of subsequent prosecution efforts.

\section{Research Approach}

A qualitative approach to the research study using unstructured narrative interviews was chosen to ensure that each woman remained in control of the research interview. Unlike semi structured interviews, these narrative interviews were unstructured, enabling the women to discuss their story in their own way, in the absence of an interview schedule with pre-set interview questions. Narratives were considered as a medium through which the women could share their stories, understandings, events, and contexts, rather than through the linear questioning approach of other interview approaches [35]. Following consent to participate, the majority of women began their accounts with how they met their partner and the progressed onto their multiple interactions with the police, sharing many of these experiences during the course of their narration. The women themselves chose what to disclose and the interviews with the principal investigator, lasted between twenty five minutes and one and a half hours. These were audio-recorded and transcribed verbatim by the primary researcher. Using a thermatic approach to analysis [36], each transcript was read several times by two members of the research team to obtain familiarity with, and an overall feeling which then led to initial codes being generated within the transcripts. A continuous and iterative process through all the transcripts continued until all the data extracts were coded across all transcripts. The codes were gathered into themes, which were then checked for their relevance to the coded data and entire data set. Using a thematic map, themes continued to develop from the initial codes, building the relationship between themes, and considering what constituted an overarching theme and what constituted a sub-theme [36]. Regular team meetings were held to discuss the developing analysis and to achieve consensus where differences in coding occurred. The final stage of the analysis resulted in the research team joining and reviewing their themes together to 
Citation: Keeling J, van Wormer, K, Taylor P (2015) Women's Narratives on their Interactions with the First Response Police Officer Following an Incidence of Domestic Violence in the UK. Social Crimonol 3: 122. doi:10.4172/2375-4435.1000122

ensure consistency, internal homogeny and external heterogeneity.

\section{Participants}

Using purposive sampling, fifteen women participated in this study, all of whom were being supported by one of two refuges in the western part of England. All the women who responded to the invitation to participate were included in the study having voluntarily accessed domestic violence shelters (residential and non-residential) and were at various stages of recovery, between 1 week post relationship and 5 years. As some had only recently left their abusive relationship and others had left a few years previously yet maintained contact with the shelters, this provided varying reflective accounts. The women's ages ranged between early twenties and late fifties. Whilst we could account for some level of diversity in our sample by recruiting across geographical and socio-economic backgrounds and ages, the women participants were primarily white British. Only four of the women were in employment at the time of the interview. The duration of domestic violence in their lives ranged between twelve months and thirty years and all had negotiated multiple interactions with a first response officer.

\section{Ethical Considerations}

Institution prior to commencement of the study. There was no compensation offered for participation and opt out was an option at any stage. Consideration of methodological and ethical considerations when researching violence against women, including protecting confidentially and ensuring the safety of the participant [37] informed this study, ensuring safety of the women participants included interviews being conducted within a refuge providing 24 hour security, confidentiality, anonymity through the use of a pseudonym, and provision of continued psychological and practical support from the refuge.

\section{Findings}

The findings are presented as three interlinked themes, which evolved out of the process of thematic analysis. The first theme revealed the interaction between the woman and the first response police officer following a domestic violence incident. At this point of crisis, the women's stories illuminated detailed descriptions of the incident, their emotional responses, and the attitudes of the attending officers. The second theme emerged when women talked about the availability of, and collection of evidence following the incident. Finally, the findings present the women's experiences of retraction of statements or withdrawal of support by the police following an assault.

\section{Initial Police Response}

The initial police response to a woman calling for help following an experience of domestic violence is significant in that they may be responding to a woman's first call to statutory authorities or during an actual incident in which she is fearful for her life. It is unlikely that this will be her first experience of domestic violence as women may have experienced up to thirty five incidences of domestic violence before they call for police support [38]. The receptiveness with which the police respond to this incident may transmit negative or positive messages to the woman and cultivate feelings of being a deserving/ undeserving victim of crime. Research has shown that a sensitive and supportive approach signals belief in the woman's words and legitimises her claims, whilst the contrasting responses minimises the experience, deterring her from seeking subsequent help and results in increased vulnerability [25]. The following excerpts from the women's narratives reveal their interactions with the first response officers following domestic violence: No I was very desperate, and the children had actually rung them [police] as well, they rung from another room saying like "daddy is hurting mum". So they [police] have come out and intervened and he [ex-partner] stood there saying, "Oh no there is nothing going on, we have just had a bit of a talk, a heated discussion but that is it". And the police opened the front door... and the police always were taken into the kitchen right ahead and I was always in the living room and they always used to go to talk to him first and then come to me right when they were leaving and not even ask me anything and not ask me what had gone wrong, what it was about, see, they saw I had handprints on my face and my eyes were red and I was crying and my eyes so swollen, you know, I can't breathe because I'm crying that hard, and they used to say, "I'm going now, everything is all right" (Lily, aged 30, 5 years post relationship). I think it is very much down to the police officer who goes out. I think a lot of it is down to attitudes as well because I'm sure they are all trained on domestic violence, but actually putting that into practice and policing is a different thing, you know. I think especially where alcohol is involved as well because a lot of women use alcohol as a coping mechanism and when you delve into their lives you can see why, but the police, as soon as they smell alcohol, it's six of one half, half a dozen of the other, isn't it, their attitude, you know (Jane, aged 40, 10 years post relationship). I'd call them up as he had done something to me and the police arrived and she [female police officer] was really horrible she was just, she was an older one, I think she didn't understand the full extent but these days the younger ones have got more training in that aspect of things and they understand it more, but this particular one she was, she was not very good... So after that I didn't have the confidence to (pause) make a statement (Vicky, aged 29, 1 year post relationship). Some of the police officers, it was like an effort just to make a statement. They would say he is only banging on the window. I said, "Well what you want him to do, kill me then and then you'll take it seriously?" (Julie, aged 41, 1 year post relationship). The narratives shown here represent how negative police responses serve to undermine a woman's autonomy and may also be interpreted as condoning the behaviour of the abusive partner. The resultant effect is for the women to remain silent, as clearly articulated by the participant where she directly states the impact of police behaviours on her feelings of eligibility; 'After that I didn't have the confidence to make a statement'. These recollections of events of the interaction between the first response police officers and the women following an incident of domestic violence reveal the first response officer's tolerance to the perpetrators' behaviour in entering into the domestic situation. These stories reveal silences in the form of non-disclosure following physical violence, and these silences are perpetuated through the lack of support and positive action offered from law enforcement personnel. These omissions (purposeful or otherwise) by attending police officers are clear and given that there may be a reluctance to report crimes of this nature to the police and a lack of confidence in the police to further these incidences to the prosecution stage, the consequences for positive relations between domestic violence victims and the police are grave. These crimes represent a 'dark figure of crime', silenced through an inappropriate or unsympathetic response. In the USA a study involving 12 major cities identified that $9.8 \%$ of women had experienced abuse within the previous two years [39]. In the UK domestic violence accounted for $16 \%$ of all reported violent incidents during 2007-08 with the majority of victims being women [40]. Given the experiences of the women in this study, these figures suggest a disparity between recorded and attended incidents, thereby making it challenging to estimate the actual incidence.

Point 5.1 of the CPS policy for Prosecuting Cases of Domestic 
Violence [28] states "[w]e will work closely with the police to make sure that all available evidence from all sources has been gathered and brought to our attention as quickly as possible". Yet these women's stories presented here reveal a disjuncture in the policepractice context. They highlight inattention towards this directive and further, a disregard or indifference towards the women's future safety. This is articulated through one of the women's interview where she reveals the desperation of her situation'what you want him to do, kill me then?'suggesting her disbelief at the police officers' response to her call for help. By having their experiences discounted, these women's fears are compounded and, further, their personal safety is compromised. Having shared their intimate experiences of police intervention, the women's stories went on to describe further episodes of domestic violence. None of the women in this study had contact with the Police Domestic Violence Units suggesting that the statutory recommendations were not followed.

\section{See No Evil, Hear No Evil}

Juxtaposed with the personal disregard for the women's experience, the first response officers attending to the women in this study appear to ignore evidential data, further negating a woman's desire to share her experiences of violence within the home. The attendance of the police at an incident of domestic violence provides a unique opportunity to gather evidence for the purposes of prosecution. The resultant evidence may then be used by the CPS, affecting the outcome of any criminal proceedings [28]. This enhanced evidence gathering underpins the subsequent legal response and plays a pivotal role in criminal prosecutions. The following excerpts from the women's stories reveal the availability of evidence presented to the first response officer. He ran when I said I had called the police, he ran and I said to them [police] the knife is in the drawer, but because the knife amnesty thing had passed they said well we would rather you not tell us about that. But I said "well why because that is the knife he has threatened me with, I am not going to go into the drawer I said because he will be watching from outside?" That was how fearful I was, I just didn't know where he was looking and earn I said, "The drawer, it's there in the drawer". So they [police] went up, opened the drawer, saw the knife and said, he said, "It's best you not telling us about that now like", he said, "because it is in your house and you are in here and you will get the consequences over that". So I said that, "My fingerprints aren't on it. I have never touched it", I said, "his prints are on it, he has touched the knife, he put it in there not me". And he said, "No, we will say nothing more" (Louise, aged 30, 5 years post relationship). He [husband] wouldn't leave me alone. I would find him asleep in my garden one morning. So I had to keep doing it [calling police] for the baby's sake. They never even came out half the time. A lot of the time they never come out. I would call them when he [husband] was banging on the windows and he came out and the police officer turned round and said, "It wouldn't do any harm just for him [husband] to see him [son]". I said "but the point is I have got an injunction against him, a restraining order. $\mathrm{He}$ is not meant to come here or anywhere near me or my little boy" but the copper turned round and said "Well it wouldn't do him any harm" (Sarah, 41, 1 year post relationship). The oppression exerted by the attending police officer negates the seriousness of the situation, as clearly demonstrated in two of the women's experiences. The failure to collect evidence following their interaction with the police thwarts any recognition of their experience within the legal processes. This lack of evidence then affects the trajectory of domestic violence cases through the legal system. The suppression of the women's concerns legitimises the action of the perpetrator and indicates a wider societal view of tolerance to domestic violence. It is argued that patriarchal societies continue to provide a safe harbour to men who choose to control, subjugate and harm their female partners [41]. Foucault's model on power and dominance is especially relevant as the women attempt to resume their relationship with their abusive partner, but have also been forced to turn to a modern institution of the police force, that may have left them exposed to revicitimisation [42]. Power and control issues are thus particularly pertinent for domestic violence survivors given their history of personal victimization and, in many cases, further violation by the social services system. Apparent within these stories is a commonality of experience: the effects of the negotiation between themselves and the first response officers. The stories reveal a conspiracy of silence by the attending officers, a denial of seeing and hearing ('see no evil, hear no evil'), leading to further derailment of the woman's self-esteem and increased self-doubt with regard to the validity of her feelings following domestic violence.

\section{Retraction of Statements/Support}

Often women may regret making a statement following an incident involving domestic violence and choose to retract their statement [26]. There are many reasons underlying this decision including fear of retaliation, lack of financial resources or wanting to maintain the relationship in some form [43]. Research suggests that this decision is affected by police practice [25] and a lack of support for such cases leading to attrition. The recording of a statement is dependent on the attending officers recognising and acknowledging the incident as a crime. They can use their discretion and base their decisions on individual ideologies or judgments about the aggressor, sometimes leading to the arrest of both the perpetrator and the female victim [44]. What follows here are the stories of participants and the influences on their decision making in respect of statements:

Well I have been to the retraction clinic with women who, who have been adamant about retracting, erm, and when they [police] have got there it is made quite clear from the outset that if they have been forced into a retraction or they think they have been forced into a retraction then they are not going to accept that because they are being coerced by the ex-partner or the ex-partner's family... it is put over in a threatening manner. The woman's defences are up and erm she's terrified of saying the wrong thing in case she can't retract it. A lot of the time it is quite threatening because the conversation goes down the line of, "Well you probably will be subpoenaed anyway so you are wasting your time"... So they [police] are quite forceful with them and try and put them off retraction which I don't think is fair because they have been through enough anyway and to me it is just another form of abuse, it is another form of pressure and control (Mary, 42 years, unknown time away from relationship). So I have made statements and retracted it. They done me for wasting police time. They knew about the violence because they were getting called out to my house all the time [sounds agitated when saying this] every week, you know what I mean, they knew but they done me for it... I know there was one policeman, his name was PC and he was nice when I was doing the statement and but when I had retracted it he was nasty, you know what I mean. That's when he did me, he gave me a $£ 80$ fine (long silence) (Daisy, 25 years, 12 months post relationship). Both of these excerpts reveal the paucity of police support at the earliest stage of the prosecution process, exacerbated by penalising these women for their retracted statements. The lack of police support is clear from both these women's stories; but the deeper and perhaps more profound issues appear to be the victim blaming and the emphasis on the woman being the criminal for retraction or indeed reporting the crime. This behaviour not only 
serves to further undermine the woman's autonomy, but also condones the behaviour of the abusive partner. Retraction of statements is only one of several reasons for the high attrition rates of domestic violence cases [26]. One UK study revealed that although an arrest occurred in three quarters of incidents of domestic violence in which an arrestable offence was committed, less than a third actually led to a criminal conviction [45]. The CPS cite the most common reasons for attrition as being the victims wanting no further action or retracting their statement [46]. High rates of attrition might be diminished through provision of effective and ongoing support to reduce the anxieties arising from interaction with the criminal justice process [45]. Counteracting retraction, the police are now instructed to assume that the woman may not support the prosecution of her violent partner when they prepare a case for prosecution [47]. Despite the intention of the CPS to prosecute a violent man, the women in our interviews reveal the personal effect on the woman.

\section{Discussion}

The women's excerpts have provided opportunities to uncover how the public-private boundaries of policing shift and dissolve, why statute concerns override the women's individual interests, and how police officers enact their first response so that they are more beneficial to themselves than the women seeking help. These intersections of organisational and interpersonal forces serve to render women invisible and reinforce victim blaming following domestic violence. Hearing women's stories of the issues of power, control and authority should facilitate law enforcement agencies understanding of how their socially ascribed role may mimic the tactical grooming used by perpetrators of domestic violence [48]. The first responding officer shapes victim perceptions of justice and may in part be due to a perceived unwillingness on the part of Criminal Justice System partners to assist in safety strategies that include the criminalization of perpetrators. Despite what might be conceivable a positive development in the policing of domestic violence, the policy of mandatory arrest and prosecution of perpetrators of domestic violence (an activity that is considerably weighted conceptually in the 'crime control' domain), carries with it unintended consequences for the women [49]. This intervention may disadvantage marginalised women further by dual arrests or unwanted interventions by the state [42]. Indeed, mandatory arrest policies meant that if the women fight back, the victims themselves risk arrest. The approach and discretion exercised by those officers making initial contact with the victim, as shown here, has a profound effect on the victim. The inappropriate action of inaction legitimises the perpetrators' behaviour. Furthermore, it is indicative of a wider societal view of tolerance to domestic violence against women. Appropriate police action following attendance at domestic violence incident signals intolerance to domestic violence, and may empower women experiencing violence and intimidation to recognise their experience as a crime. The failure of the police officers to intervene and to arrest perpetrators endorses the oppression of women [50]. These negative responses also serve to undermine the women's autonomy, causing the women to remain silent and increasing their vulnerability. The collection of evidence following domestic violence underpins both the recognition of domestic violence as a crime conceptually and the prospective process of legal redress. The women's stories reveal a disregard for an adherence to 'due process' principles and, further, a disregard for the women's future safety. In liberal-democratic countries, where the operations of agencies of the state come to represent meaning (e.g. through the enforcement of legislative structures etc.), the resultant effect is suggestive of a societal and legislative tolerance to domestic violence, a society which provides a safe harbour to men who choose to control, subjugate and harm their female partners. Appropriate police action following domestic violence signals intolerance to this pandemic social problem, and may empower a women by acknowledging the criminality of the perpetrators actions. The understanding of the various causes and full consequences of retraction remains limited [26]. This paper attempts to offer some explanation to this action, revealing both personal implications for the woman, and the change in police attitude after this action has taken place. Studies have revealed the benefits of a coordinated community response to domestic violence [29]. Additionally, protection work provides support for all victims through the criminal and civil justice systems, from the initial response to court proceedings [18]. Thus, an effective criminal justice system and a cohesive support network for women will serve to strengthen the woman's resolve, and create a conductive personal and societal approach to domestic violence. Contrary to the objectivity of policing domestic violence, police officers may be imbued with andro centricism, of failing to recognize and negotiate the dynamics of subjugation. It is asserted that [46] "[t]he quality of the response of an officer attending a domestic abuse incident is just as important as the speed with which they turn up. However, the routes to first response police behaviours and interactions are broad and multifarious, and an insight into the context in which policing takes place within may be valuable. The production of less than desirable outcomes for the women shown here and potentially more widely, are symptomatic of several circulating influences bearing down on police work. Observing the social and cultural context of policing is an important analytical lens by which to establish barriers and blockages to positive change. Whilst policy may promote or direct reforms to police practice, the nuances of the informal backcloth of police culture and value-sets are worthy of consideration also. Indeed, police culture is notoriously difficult to define [51], yet understanding its constituent parts, operating contexts and influences can be opportune. Individual officer behaviours and their alignment or differentiation to dominant cultural value sets is also potentially influential in the experience of a domestic violence victim. As discussed earlier, police culture is a fundamental mechanism in the production of powerful analogies of victims and perpetrators, but operates alongside, and in reaction to, set role mandates. Whilst the policy rhetoric of eligibility for domestic violence victims exists, the translation of this into routine police practice may be diverted. The difficulties of policing within the privacy of the 'home', rather than the conventional public space where policing ordinarily takes place may be a potential catalyst for less-positive outcomes. Similarly, the gender asymmetry operating in society is mirrored in a profession that operates the delivery of sanctions within it. Indeed, the masculine values that pervade policing in the UK and elsewhere have been noted as oppressing women in policing [52] and so there is room to suggest that such values are to be found also in the outward functioning behaviours of the police. The narratives presented here also support assertions that domestic violence challenges cultural ideas of what constitutes 'real' police work [53]. The Government and its legislation may be defined by aiming to shape, guide or affect the conduct of some person or persons [53] and this conduct serves to regulate statutory workers such as the police. As the responsibility for identification of, and support for, women experiencing domestic violence expands, so has the requirements for this statutory agency to develop policies to define accessibility rights to their mechanisms of support [42]. Through this regulation, women's experiences may become hidden within this dimension in what Garland [54] argues is a culture of control. 
Citation: Keeling J, van Wormer, K, Taylor P (2015) Women's Narratives on their Interactions with the First Response Police Officer Following an Incidence of Domestic Violence in the UK. Social Crimonol 3: 122. doi:10.4172/2375-4435.1000122

Page 7 of 8

\section{Conclusions}

Responses to victimisation by statutory agencies, as seen in cases of domestic violence, are illustrative of instances where the competing demands of different value systems in the criminal justice arena become visible. Whilst analytical propositions are useful in tracing some of the less-than-positive experiences of victim's interactions with first response officers it is the use of narratives, the sharing of personal stories naming and defining societal issues previously unmentioned, that offers an important insight and contribution to experiences. In this way, when women's interactions with first response officers are told, the phenomena can no longer be ignored. We need to understand the dynamics of the problem to be able to develop an appropriate response and it is in the hearing of these women's stories that we begin to understand the complexity of the issue. Although these findings represent a small sample of women, they are essential in the initiation of a dialogue which draws attention to the dichotomous first response officers' reactions, and from which the milieu has now been provided to engage in more extensive research. Fundamental principles of 'due process' may be deeply impressed in the official rhetoric of how domestic violence should be policed, although problems in the collection of evidence remain. Moreover, there is clear evidence in mandatory arrest policies of 'crime control' principles where the demand for prosecution finality is high despite potential unintended consequences along the way. In such an ideological struggle, police inaction may be indicative of first response officer's occupational dilemmas surfacing. Indeed, it may be convenient and less troublesome to take no action, however amidst a professional context of divergent aims and values and the absence of clearly articulated practice guidance, inaction may be the likely consequence. Studies have established the benefits of a co-ordinated community response to domestic violence [55,56], an effective criminal justice system and a cohesive support network for women which then serves to strengthen woman's resolve and create a conducive personal and societal approach to domestic violence. It is therefore argued that continuing professional development training for all police officers around the issues of behavioural responses to women experiencing domestic violence, attitudes and assessment by the first response officer, observations and support strategies, should integrate the women (service users) themselves.

\section{Limitations}

The main limitation is the narrow context of the study as the sample was drawn from a predominantly white British population and recruited women who self-disclosed domestic violence. Whilst acknowledging the limited generalisability of the study, it is hoped that the findings may still be applicable to a broader audience involved in supporting survivors of domestic violence, and these women's experiences contribute to the limited literature surrounding interactions with a first response officer. In this study we were able to account for some level of diversity in our sample by recruiting across geographical and socio-economic backgrounds and ages. Despite this, the salience of the findings to other settings may be limited through the absence of women from culturally and linguistically diverse backgrounds. Our inability to extend sample diversity to participant cultural background raises questions around accessibility of mainstream DV services to diverse women. The similarities in the experiences of the women across the UK do give us hope, however, that we have been able to elicit important experiential components of the interaction of women and the first response officer following an incident of domestic violence.

\section{References}

1. Tong R (1995) Feminist Thought: A Comprehensive Introduction. London: Routledge.

2. Crown Prosecution Services (2005) Charging Standard. Oxford, United Kingdom.

3. Groves N, Thomas T (2014) Domestic violence and criminal justice. London, United Kingdom: Routledge.

4. Richards L, Latchford S, Stratton S (2008) Policing Domestic Violence. Oxford, United Kingdom: Oxford University Press.

5. Grady A (2002) Female-on-male domestic abuse: uncommon or ignored? New visions of crime victims.

6. Eitle D (2005) The influence of mandatory arrest policies, police organizational characteristics, and situational variables on the probability of arrest in domestic violence cases. Crime and Delinquency 51: 573-97.

7. Hoyle C (1998) Negotiating domestic violence: police, criminal justice, and victims. Oxford, United Kingdom: Clarendon Press.

8. Human Rights Act 1998: Elizabeth II. Chapter 42. (1998). London: The Stationery Office.

9. Her Majesty's Court Service (2005) Serious Organized Crime and Police.

10. Barrett BJ, Pierre MS, Vaillancourt N (2011) Police response to intimate partner violence in Canada: Do victim characteristics matter? Women and Criminal Justice 21: 38-62.

11. Sokoloff NJ, Dupont I (2005) Domestic Violence at the Intersections of Race, Class, and Gender Challenges and Contributions to Understanding Violence Against Marginalized Women in Diverse Communities. Violence Against Women11: 38-64.

12. Goodman LA, EpsteinD (2008) Listening to battered women: A survivorcentered approach to advocacy, mental health and justice. Psychology of women Washington DC: American Psychological Association.

13. Home Office. Justice for all. (Cm 5563)2002 26/05/14. Available from http://www.cjsonline.gov.uk/downloads/application/pdf/CJS\%20White $\% 20$ Paper\%20

14. Vallely C (2005) Evaluation of Domestic Violence Pilot Sites at Caerphilly (Gwent) and Croydon London: Crown Prosecution Service.

15. Walby S (2009) Her Majesty's Inspectorate of Constabulary Everyone's business: Improving the police response to domestic abuse.

16. Home Office (2003) Safety and justice: the government's proposals on domestic violence.

17. Home Office (2004) Sections 12 and 13 of the Domestic Violence, Crime and Victims Act London.

18. Fisher C, Keeling J, Tsou C, Gausia K (2014) Navigating Complexity and the Unknown: The Journey to Violence-Free Lives for Australian Midlife Women Who Have Experienced Domestic Violence. Manuscript submitted for publication.

19. Criminal Justice System (2005) No Witness, No Justice" CPS/ACPO/HO/ OPSR Victim and Witness Care Project Minimum Requirements. London.

20. Criminal Justice System (2008). Implementing and complying with the Witness Charter. Operational guidance for police service managers.

21. Crown Prosecution Service (2009) CPS Policy for Prosecuting Cases of Domestic Violence. London: CPS Policy Directorate.

22. Hester M (2006) Making it through the Criminal Justice System: Attrition and Domestic Violence. Social Policy and Society 5: 79-90.

23. Koss MP (2000) Blame, shame, and community: Justice responses to violence against women. American Psychologist 55: 1332-43.

24. Harne L, Radford J (2008) Tackling domestic violence-theories, policies and practice. Suffolk: McGraw Hill.

25. Robinson A, Cook D (2006) Understanding Victim Retraction in Cases of Domestic Violence: Specialist Courts, Government Policy, and Victim Centred Justice. Contemporary Justice Review 9: 89-213.

26. Crown Prosecution Service (2008) Violence against Women crime report. 
Citation: Keeling J, van Wormer, K, Taylor P (2015) Women's Narratives on their Interactions with the First Response Police Officer Following an Incidence of Domestic Violence in the UK. Social Crimonol 3: 122. doi:10.4172/2375-4435.1000122

Page 8 of 8

27. Crown Prosecution Service (2008) CPS Policy for Prosecuting Cases of Domestic Violence. In: Branch CC, editor. London P 18.

28. Robinson AL (2000) The effect of a domestic violence policy change on police officers' schemata. Criminal Justice and Behavior 27: 600-24.

29. Packer $\mathrm{H}$ (1964) Two models of the criminal process. University of Pennsylvania Law Review 113: 1-68.

30. Hungerford-Welch P (2014) Criminal Procedure and Sentencing. 8th ed. Oxon NY: Routledge

31. Stinson PM, Liederbach J (2013) Fox in the Henhouse: A Study of Police Officers Arrested for Crimes Associated With Domestic and/or Family Violence. Criminal Justice Policy Review 24: 601-25.

32. Lonsway KA (2006) Policies on Police Officer Domestic Violence: Prevalence and Specific Provisions Within Large Police Agencies. Police Quarterly 9: 397-422.

33. Lonsway K, Weterdorf D, Conis P (2003) Lessons learned from Tacoma: the problem of police officer domestic violence. Law Enforcement Executive Forum 3: $27-36$.

34. Ribbens J, Edwards RO (1998) Feminist Dilemmas in Qualitative Research Public Knowledge and Private Lives. London: Sage Publications

35. Braun V, Clarke V (2006) Using thematic analysis in psychology. Qualitative Research in Psychology 3:77-101.

36. World Health Organisation (2001) Putting women's safety first: Ethical and safety recommendations for research on domestic violence against women.

37. Jaffe P, Wolfe DA, Telford A, Austin G (2006) The impact of police charges in incidents of wife abuse. Journal of Family Violence 1: 37-49.

38. Walton-Moss BJ, Manganello J, Frye V, Campbell JC (2005) Risk factors for intimate partner violence and associated injury among urban women. Journal of Community Health 30: 377-89.

39. Povey D, Coleman K, Kaiza P, Roe S (2009) Homicides, Firearm Offences and Intimate Violence London: Home Office.

40. Bennett JM (2006) Patriarchal Equilibrium. In: Bennett JM, editor. History matters: patriarchy and the challenge of feminism. Philadelphia: university of Pennsylvania Press p: 56.

41. Bumiller K (2008) The sexual violence agenda. In: Bumiller K, editor. In an abusive state: How neoliberalism appropriated the feminist movement against sexual violence. Durham, NC: Duke University Press p: 1-15.

42. Gill A (2004) Voicing the silent fear: South Asian Women's Experiences of Domestic Violence. The Howard Journal 143: 5.

43. Ferraro KJ (1989) Policing woman battering 36: 61-74.

44. Hester M, Westmarland N (2005) Tackling Domestic Violence: effective interventions and approaches. London HMSO: Home Office Research Study 290.

45. Her Majesty's Crown Prosecution Service Inspectorate (2004) Violence at Home: a joint thematic inspection and prosecution of cases involving domestic violence. In: Inspectorate HMsCPS, editor. London:

46. Starmer QCK (2011) Domestic Violence: the facts, the issues, the futureSpeech by the Director of Public Prosecuions. London: The Crown Prosecution Service.

47. Keeling J, Fisher C (2012) Women's Early Relational Experiences That Lead to Domestic Violence. Qualitative Health Research 22: 1559-67.

48. van Wormer K, Roberts AR (2009). Death by domestic violence: Preventing the murders and murder-suicides. Westport, CT: Greenwood.

49. Hanmer J, Radford J, Stanko (1989) Women and Policing in Britain. Women, Policing and Male Violence. London: Routledge

50. Chan J (1996) Changing police culture. British Journal of Criminology 36: 109-34.

51. Franklin CA (2007) Male peer support and the police culture: understanding the resistance and opposition of women in policing. Women and Criminal Justice 16: 1-25.

52. Burchell G, Gordon C, Miller P, Gordon C (1991) Governmental rationality: an introduction. The Foucault Effect: Studies in Governmentality. Chicago: The University of Chicago Press p: 2.

53. Garland D (2001) The Culture of Control: Crime and social order in contemporary society. Chicago: University of Chicago Press.

54. Robinson L (2006) Reducing Repeat Victimization Among High-Risk Victims of Domestic Violence. Violence Against Women 12: 761-88.

55. Shepard MF, Falk DR, Elliott BA (2002) Enhancing Coordinated Community Responses to Reduce Recidivism in Cases of Domestic Violence. Journal Interpersonal Violence 17: 551-69 